\title{
Original Congenital diaphragmatic hernia: A fetal study
}

\author{
Amrutha KV, Anshu Sharma, Joseph Abraham, Mahesh \\ Sharma
}

ABSTRACT

Department of Anatomy, Government

Medical College and Hospital,

Chandigarh, India.

Correspondence: Amrutha KV

Email: amruthavilasan@gmail.com
Background: Congenital diaphragmatic hernia $(\mathrm{CDH})$ is one of the rare types of malformations in the new born. The estimated incidences of $\mathrm{CDH}$ is 1 in 2000 to 5000 live births.

Methods: This study was conducted on 1000 fetuses obtained from the Department of Obstetrics and Gynecology, Government Medical College and Hospital, Chandigarh. The autopsies were done in the Department of Anatomy, GMCH Chandigarh.

Results: In our present study, the incidence of CDH was $1.6 \%$ (out of 1000 fetuses, 16 fetuses had CDH) among all the cases. The left-sided defect was seen in $75 \%$ of the cases, right sided in $12.5 \%$ of cases and bilateral and central tendon defect in $1 \%$ of the cases. Associated anomalies were noted in each case.

Conclusion: Prenatal diagnosis of $\mathrm{CDH}$ is important to detect and avoid further complications in life.

KEYWORDS: Congenital diaphragmatic hernia; pulmonary hypoplasia; herniation.

\section{Introduction}

Diaphragm is the musculofibrous partition between the thorax and the abdominal cavity. Defect in the diaphragm may causes herniation of structures of the abdominal cavity into the thoracic cavity. This defect may be congenital or acquired.

Congenital Diaphragmatic Hernia $(\mathrm{CDH})$ permits the herniation of abdominal contents into the thorax through an orifice in the diaphragm; it most commonly occurs on the posterolateral aspect on the left side. ${ }^{1}$
According to Torf et al, the prevalence of defects in the diaphragm among newborns is 1 in $3000 .^{2}$ Left-sided posterolateral hernias are more common $(85 \%)$ than right sided $(15 \%)$ because the liver plugs the defect 3 whereas central tendon defects and bilateral $\mathrm{CDH}$ are very rare $(2$ to $3 \%$ ). The most common anomaly associated with $\mathrm{CDH}$ is pulmonary hypoplasia which is due to pressure effects from herniated structures such as the liver, stomach, spleen and intestine. ${ }^{4}$ This leads to poor development 
of the terminal bronchioles, alveoli and pulmonary vessels resulting in respiratory failure soon after birth. ${ }^{5,6}$ According to Sweed et al, other congenital anomalies associated with $\mathrm{CDH}$ accounts for about 30 to $40 \%$ of cases, which include neural tube and cardiac defects, chromosomal and craniofacial anomalies, omphalocoele and urinary tract and gastrointestinal defects. ${ }^{7}$ This study evaluated prevalence of congenital diaphragmatic hernia in aborted fetuses.

\section{Materials and Methods}

This study was conducted on 1000 fetuses obtained from the Department of Obstetrics and Gynecology of the Government Medical College and Hospital, Chandigarh from 2008 to 2015 . These fetuses were obtained as a result of spontaneous abortions and IUDs. In some cases, MTP was indicated after the detection of defect on antenatal ultrasound. Out of 1000 fetuses, 16 were found to have congenital diaphragmatic hernia. The family history and medical and occupational history of parents was noted. Obstetric and antenatal history of each mother was noted. Each fetus was examined externally. Photographs and radiology of each fetus with the defect was also done. Autopsy was performed following the routine procedure. The internal examination was done and other organs/ systems with any anomaly were also noted and correlated with the history.

\section{Observations}

Out of 1000 fetuses, $16(1.6 \%)$ were found to have congenital diaphragmatic hernia. The type of defect and its frequency are as shown below .

\begin{tabular}{|l|l|}
\hline Type of defect & No of cases (\%) \\
\hline Left sided Bochdalek hernia (Figure 1) & $12(75 \%)$ \\
\hline Right sided Bochdalek hernia (Figure 2) & $2(12.5 \%)$ \\
\hline Bilateral hernia (Figure 3) & $1(6.25 \%)$ \\
\hline Central tendon defect & $1(6.25 \%)$ \\
\hline
\end{tabular}

\begin{tabular}{|l|l|}
\hline Associated anomalies & No of cases (\%) \\
\hline Cardiovascular & $4(25 \%)$ \\
\hline Respiratory & $9(56 \%)$ \\
\hline Neural tube defects & $10(62.5 \%)$ \\
\hline Gastrointestinal & $8(5 \%)$ \\
\hline Urogenital & $2(12.5 \%)$ \\
\hline Musculoskeletal & $10(62.5 \%)$ \\
\hline SUA & $2(12.5 \%)$ \\
\hline
\end{tabular}

\begin{tabular}{|l|l|}
\hline Herniated structures & No of cases (\%) \\
\hline Liver & $15(93 \%)$ \\
\hline Gall bladder & $1(6.25 \%)$ \\
\hline Stomach & $12(75 \%)$ \\
\hline Spleen & $11(68.7 \%)$ \\
\hline Small intestine & $7(43.7 \%)$ \\
\hline Appendix & $1(6.25 \%)$ \\
\hline Kidney & $1(6.25 \%)$ \\
\hline
\end{tabular}

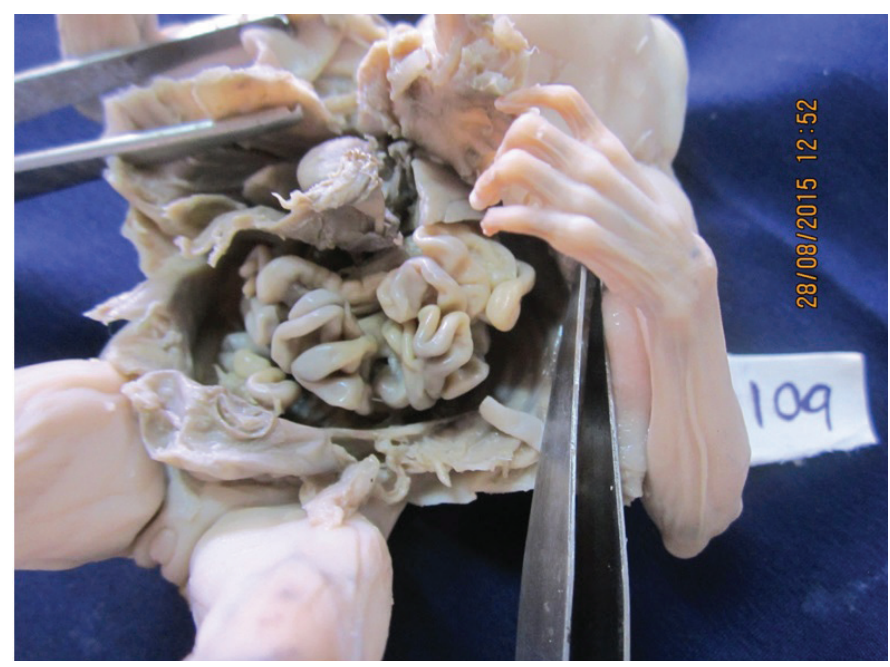

Figure 1: Left sided diaphragmatic hernia.

\section{Discussion}

The diaphragm is a musculofibrous partition that separates the thorax from the abdominal cavity. It consists of two cupolae and a central tendon. ${ }^{8}$ Development of the diaphragm starts by the third week and is completed by the eighth week of intrauterine life. ${ }^{9}$ 


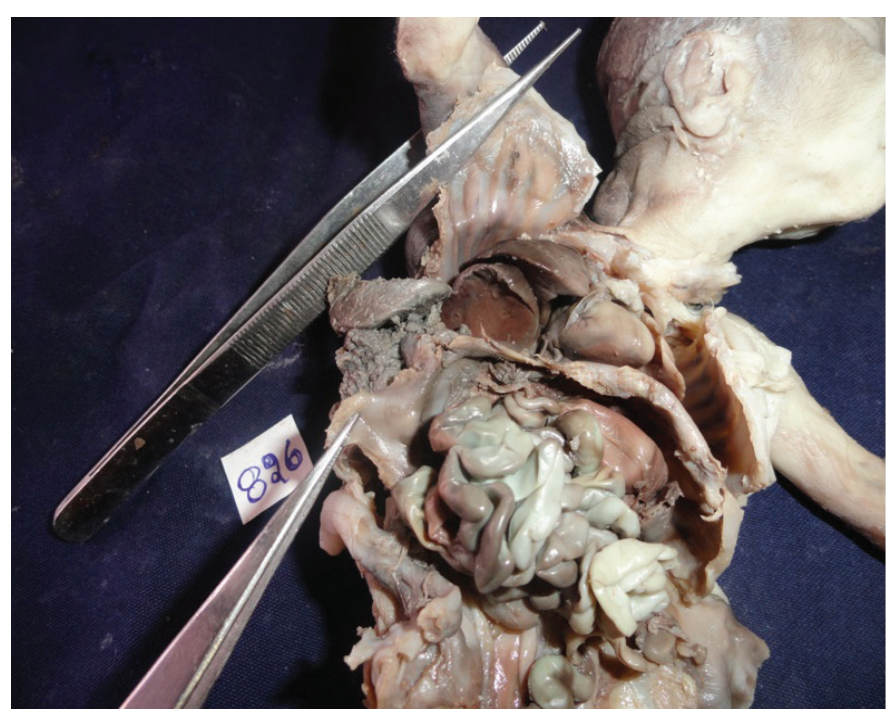

Figure 2: Right sided diaphragmatic hernia with lateral body wall syndrome.

$\mathrm{CDH}$ is one of the most common malformations in the new born and is commonly caused by failure of closure of one or both pleuro-peritoneal canals. ${ }^{10}$ There are four types of congenital diaphragmatic hernia: (a) Hiatal hernia : herniation through a congenitally large esophageal orifice (3\%) (b) Bochdalek Hernia (posterolateral defect): this is the most common type of congenital hernia and is seen mostly in males. Incidence of bilateral hernia is $5 \%$, while unilateral hernia is seen in about $90 \%$ of cases. (c) Morgagnian hernia: the defect is in the anterolateral part of the diaphragm. This defect has a female preponderance. It accounts for $2 \%$ of all the cases. (d) Defects occurring in the central tendon: It is the rarest type of diaphragmatic hernia reported. ${ }^{11}$

IN 1960, Lazarius reported the first case when he found the defect accidentally during autopsy. ${ }^{12}$ In a study conducted on $\mathrm{CDH}$ in Australia, it was observed that about 70 to $75 \%$ of cases had posterolateral defects, 23 to $28 \%$ Morgagnian hernia and only 2 to $7 \%$ were with central defect. ${ }^{13}$ Another study by Benjamin et al mentioned that left-sided posterolateral hernia was more common (85\%) than right-sided (13\%). The incidence of bilateral hernia was $2 \%$. They also noted a male preponderance in leftsided hernia with a male to female ratio of 3:214 whereas the right sided hernia had a male to female ratio of 3:111. A retrospective study of neonatal autopsies done in New

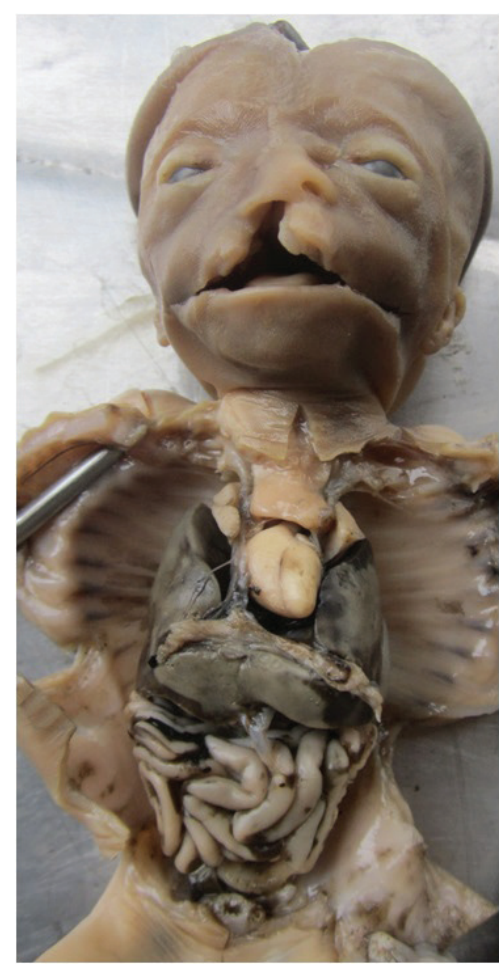

Figure 3: Bilateral congenital diaphragmatic hernia.

Delhi during the span of 30 years encountered 10 cases of $\mathrm{CDH}$ among 588 autopsies done. They concluded that $\mathrm{CDH}$ accounted for about $1.7 \%$ of all cases. They also noted that there was no relation between any possible maternal factors and CDH. Male female ratio was 7:3. The left lobe of the liver and intestinal loops were the common herniating structures. ${ }^{15}$

Studies have mentioned that left-sided Bochdalek hernia are more common that right-sided. Levy et al reported that the frequency of left-sided posterolateral diaphragmatic defects was 8 times more than right-sided hernias in newborns. ${ }^{16}$ In our study, we noted 14 cases of unilateral CDH out of which 12 cases were left-sided. The left side of the diaphragm closes later which may be the reason why the $\mathrm{CDH}$ is seen more on left side. ${ }^{17}$ We noted a case of bilateral CDH with herniation of the liver, coils of the intestine, the stomach and the spleen. Less than $1 \%$ of neonates had bilateral $\mathrm{CDH}$ as reported. ${ }^{18}$

Right-sided posterolateral hernia is rare compared to left-sided. A protective effect of the liver developing in the septum transversum and early closure of the pleuroperitoneal opening can explain why right-sided 
$\mathrm{CDH}$ occurs early ${ }^{19}$ although apart from this, the presence of a right-sided $\mathrm{CDH}$ could also be missed because of similar echogenicity of herniated liver with that of the lung. ${ }^{20}$ Two cases of right-sided $\mathrm{CDH}$ with herniation of the liver and gall bladder were part of our study group.

The diaphragmatic defects can be detected as early as in the second trimester by ultrasonography. ${ }^{21}$ Three cases of $\mathrm{CDH}$ in our study were diagnosed ultrasonographically. The rest of the cases were detected during autopsy. By finding out direct signs like the presence of abdominal organs in the thorax and indirect signs like mediastinal shifts, abnormal cardiac axis and the presence of polyhydramnios on ultrasound, a diagnosis of CDH can be made. Van den Hout L described a case series where a prenatal diagnosis of $\mathrm{CDH}$ was missed in 40 per cent of cases and these infants postnatally showed acute respiratory distress, absence of breath sounds on the ipsilateral side, shifted cardiac sounds and bowel sounds in the chest, a barrel-shaped chest and a scaphoid abdomen. ${ }^{22}$ Jain et al showed that herniation of the liver detected by radiological investigations may be associated with a poor prognosis. ${ }^{9}$

\section{Conclusion}

Clinicians should be careful regarding bilateral $\mathrm{CDH}$ even though it is an extremely rare congenital malformation since this is one congenital anomaly which can be detected and treated prenatally to reduce mortality and postnatal outcomes. Genetic factors play an important role in the development of $\mathrm{CDH}$. Parents should be informed about the severity of $\mathrm{CDH}$, the expected pre- and post-natal events and the risk of poor outcomes including death and the various long-term morbidities. ${ }^{23}$

\section{References}

1. Tovar JA. Congenital Diaphragmatic Hernia. Orphanet Journal of Rare Diseases. 2012;7:1-15.

2. Torfs CP, Curry CJ, Bateson TF, Honore LH. A populationbased study of congenital diaphragmatic hernia. Teratology. 1992,46:555-65.

3. Narkhede A, Shrikhande DY, Nigwekar P, Yadav S, Kasodariya H. Right sided congenital diaphragmatic hernia: a rare case report. Int $J$ Med Res Health Sci. 2014;3(1):193-194.

4. Kluth D, Tander B, von Ekesparre M et al. Pediatr Surg Int. 1995;10(1):16-22.

5. Kitagawa M, HislopA, BoydenEA, Reid L. Lung hypoplasia in congenital diaphragmatic hernia. A quantitative study of airway, artery, and alveolar development. Br J Surg. 1971;58:342-6.

6. Levin DL. Morphologic analysis of the pulmonary vascular bed in congenital left-sided diaphragmatic hernia. J. Pediatr. 1978;92:805-9.

7. Sweed Y, Puri P. Congenital diaphragmatic hernia: influence of associated malformations on survival. Arch Dis Child. 1993;69:68-70.

8. Drake RL, Vogl W, Mitchell AWM, Gray H. Gray's Anatomy forstudents.1st ed. Philladelphia:Churchill Livingstone/Elsevier. 2005. p.134-135.

9. Jain S, Satani S, Khandelwal S, Dandona S, Gursale A.Right sided congenital diaphragmatic defect with liver hernia:A Case Report. Int Arch Integ Med. 2014;1:75-79.

10. Sadler TW.Langman's Medical Embryology in Body cavities.11ed. New Delhi: Lippincott Williams and Wilkins, Wolters Klumer Health India Pvt Ltd. 2006. p.159-162.

11. Aleksandra NM, Ruben Quintero : Diaphragmatic hemia with Novakov. Available from http://www.thefetus.net. 1 2005-05-29-17 .

12. Hekmantia A, Mc Hugh K. Congenital Diaphragmatic Hernia: emedicine Radiology, Cardiac disease and Critical care. 2008;5-6.

13. Veenma DC, de klein A, Tibboel D. Developmental and genetic aspects of congenital diaphragmatic hernia. Pediatr Pulmonal. 2012;47:534-45.

14. Benjamin DR, Juul S, Siebert JR. Congenital posterolateral diaphragmatic hernia; associated malformations. $J$ Pediatr Surg. 1988;23:899-903.

15. Bajaj P, Tayal, Logani KB, Bhan S. Congenital diaphragmatic hernia: a retrospective autopsy study. Indian Pediatrics.1991;28:495-499.

16. Levy JL Jr, Guyner W A, Louis JE. Bilateral congenital diaphragmatic hernia through the foramina of Bochdalek. J Pediatr Surg. 1969;4:557-9.

17. Standring S, Collins P, Heely LC, Johnson D, Shah P, Wigley C. Gray's Anatomy in Development of trachea, lungs and diaphragm. 39th ed. Edinburgh, London, New York, Oxford, Philadelphia, St. Louis, Sydney, Toronto: Elsevier Churchill Livingstones Publication. 2005. p. 1092-93. 
18. Neville HL, Jaksic T, Wilson JM, Lally PA, Hardin WD Jr, Hirschl RB et al. Bilateral congenital diaphragmatic hernia. J Pediatr Surg. 2003;38:522-4.

19. Berman L, Stringer D, Ein SH, Shardling B. The late presenting paediatric bochdalek hernia: a 20 year review. J Paediatric Surg. 1988;23(8):735-9.

20. Graham G, Devine PC. Antenatal diagnosis of congenital diaphragmatic hernia. Semin Perinatol. 2005;29:69-76.
21. Harrison MR, Adzick NS, Nakayama DK, deLorimier AA. Fetal diaphragmatic hernia: fetal but fixable. Semin Perinatol. 1985;9:103-12.

22. van den Hout L, Sluiter I, Gischler S, De Klein A, Rottier R, Ijsselstijn $\mathrm{H}$ et al. Can we improve outcome of congenital diaphragmatic hernia? Pediatr. Surg. Int. 2009;25:733-43.

23. Iritani I. Experimental study on embryogenesis of congenital diaphragmatic hernia. Anat Embryol. 1984;169:133-9. 